\title{
THE APRIL MEETING AT BERKELEY
}

The five hundred sixty-ninth meeting of the American Mathematical Society was held at the University of California in Berkeley, California on Thursday, Friday and Saturday, April 21, 22 and 23, 1960. There were 208 registrants at this meeting, 180 of whom were members of the Society.

By invitation of the Committee to Select Hour Speakers for Far Western Sectional Meetings, and sponsored by the Society with the financial aid of the Air Force Office of Scientific Research, a Symposium on Partial Differential Equations was held on Thursday and Friday in conjunction with the meeting. The Program Committee for this Symposium consisted of Professors C. B. Morrey, Jr., Chairman, David Gilbarg, Louis Nirenberg and P. C. Rosenbloom. The first session of the Symposium, presided over by Professor Bernard Friedman, consisted of a 45 minute address by Professor C. B. Morrey, Jr., University of California at Berkeley, entitled Extensions and applications of the DeGiorgi-Nash results, followed by three 20 minute talks: Professor J. B. Serrin, University of Minnesota, on Dirichlet's principle in the calculus of variations, Professor Nachman Aronszajn, University of Kansas, on Associated spaces, interpolation theorems, and the regularity of the solutions of differential equations, and Professor A. P. Calderón, Massachusetts Institute of Technology, on Lebesgue spaces of differentiable functions and distributions. The second session of the Symposium was led by Professor Morrey and it included a 45 minute talk by Professor P. C. Rosenbloom, University of Minnesota, on Partial differential equations in a complex domain, plus three 20 minute addresses: Professor F. E. Browder, Yale University, on $A$ priori estimates for elliptic and parabolic equations, Professor François Trèves, University of California at Berkeley, on Differential equations in Hilbert spaces, and Professor H. F. Weinberger, University of Maryland, on $A$ maximum property of multidimensional Cauchy problems. Professor Rosenbloom presided at the third session of the Symposium. It consisted of a 45 minute address by Professor Louis Nirenberg, New York University, entitled Comments on elliptic partial differential equations, and three 20 minute addresses: Professor Martin Schechter, New York University, on Some unusual boundary value problems, Professor Avner Friedman, University of Minnesota, on $A$ new proof and generalizations of the Cauchy-Kowalewski theorem, and Professor Fritz John, New York University, on Regularity of continuation of solutions. The final session of the Symposium, presided 
over by Professor Nirenberg, included a 45 minute talk by Professor David Gilbarg, Stanford University, on Some properties of linear elliptic equations with rough coefficients, and three 20 minute addresses: Professor Robert Finn, Stanford University, on Estimates at infinity for steady-state solutions of the Navier-Stokes equations, Professor E. Heinz, Stanford University, on Interior estimates for solutions of elliptic Monge-Ampère equations, and Professor H. O. Cordes, University of California, Berkeley, on Zero-order a priori estimates for solutions of elliptic differential equations.

The Proceedings of this Symposium will be published in book form by the Society at an early date.

By invitation of the Committee to Select Hour Speakers for Far Western Sectional Meetings, Professor F. B. Fuller of the California Institute of Technology addressed the Society on Saturday afternoon. His talk was entitled Fixed points of multiple-valued transformations. Professor Fuller was introduced by Professor E. H. Spanier.

There were six sessions for contributed papers on Saturday with Dr. J. E. Maxfield and Professors L. W. Anderson, D. S. Carter, W. T. Keyner, M. J. Kingston and G. E. Latta presiding.

R. S. Pierce, Associate Secretary 